\title{
Percutaneous Removal of Gallstones Under Fluoroscopy Guidance in High-risk Patients with Acute Cholecystitis
}

\begin{abstract}
We report our technique of percutaneous removal of gallstones in three elderly patients with acute calculus cholecystitis who were not surgical candidates due to multiple comorbidities. The procedure is performed under local anesthesia using fluoroscopic and choledochoscopic guidance. All patients had uneventful recovery and were discharged home in 3-4 days and fallow up at a low and high surveillance by ultrasound at 3 and 6 months interval.
\end{abstract}

Keywords: Calculus cholecystitis, electrohydraulic lithotripsy, extra shock wave lithotripsy, octogenarians

\section{Introduction}

Laparoscopic

cholecystectomy,

introduced in 1985, has largely replaced the conventional method of open cholecystectomy. ${ }^{[1]}$

Several nonoperative techniques for gallstone removal were developed for high-risk patients deferred for general anesthesia. Burhenne et al. in 1975 first introduced the use of electrohydraulic lithotripsy in the biliary tree. ${ }^{[2]}$ Burhenne and Stoller in 1985 introduced interventional radiological technique of percutaneous removal of gallstones under fluoroscopy in critically sick patient. ${ }^{[3]}$

\section{Case Report}

The first patient is a 90-year-old male with severe ischemic heart disease. Echocardiogram showed ejection fraction of $15 \%$ and severely impaired left ventricular systolic function. The second patient is 85 -year-old male with history of stroke, chronic obstructive airway disease, and hyperlipidemia. The third patient is 83-year-old female with history of renal failure and right ventricular dysfunction due to pulmonary hypertension.

After multidisciplinary consultation including cardiologist, pulmonologist, critical care, and gastroenterologist, it was decided to proceed for percutaneous cholecystolithotripsy (PCCL). A routine

This is an open access article distributed under the terms of the Creative Commons Attribution-NonCommercial-ShareAlike 3.0 License, which allows others to remix, tweak, and build upon the work non-commercially, as long as the author is credited and the new creations are licensed under the identical terms.

For reprints contact: reprints@medknow.com blood investigation including white cell count, hemoglobin, renal and liver panel, and coagulation screen was carried out. Prophylactic broad-spectrum antibiotics coverage was given pre- and post-intervention.

Percutaneous cholecystolithotripsy (PCCL) was performed either through transperitoneal or through transhepatic approach. We preferred transperitoneal approach for all our patients, which has fewer complications as compared to transhepatic. The procedure was carried out under local anesthetic using $1 \%$ lignocaine and midazolam for moderate sedation.

Gallbladder was accessed percutaneously under ultrasound and fluoroscopic guidance with 21-gauge $15 \mathrm{~cm}$ long Chiba needle using standard technique. The tract was dilated with an 8-F coons dilator (Cook, Bloomington, Indiana, USA). For the initial catheter insertion, we used 8.5 Fr, $15 \mathrm{~cm}$ cope loop catheter (Cook). The catheter was connected to a drainage bag, and cholangiogram was performed after 48-72 h. Subsequently, dilatation of the sinus was done up to $18 \mathrm{Fr}$ over a period of 6-8 weeks in all patients and one patient required further dilatation to $22 \mathrm{Fr}$ using nephroMax (High-Pressure Balloon, Boston Scientific, USA). The stones were removed successfully percutaneously by baskets, irrigation, and mini choledocoscopy in two patients [Figure 1]. One patient with

\footnotetext{
How to cite this article: Al Nammi A, Cheema A, Al Nammi M, Chaudhry I. Percutaneous removal of gallstones under fluoroscopy guidance in high-risk patients with acute cholecystitis. Arab J Intervent Radiol 2017;1:30-2.
}

\section{Ahmed Al Nammi, Ahsan Cheema, Mohanned Al Nammi, Ikram Chaudhry}

Department of Medical Imaging, Interventional Radiology Unit, King Fahad Specialist Hospital Dammam, Saudi Arabia
Address for correspondence: Dr. Ahmed Al Nammi, Department of Medical Imaging, Interventional Radiology Unit, King Fahad Specialist Hospital Dammam, Saudi Arabia. E-mail: alnammi2000@gmail.com

Access this article online Website: www.arabjir.com

Quick Response Code:

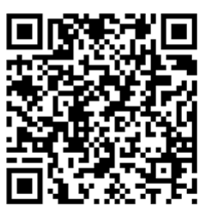




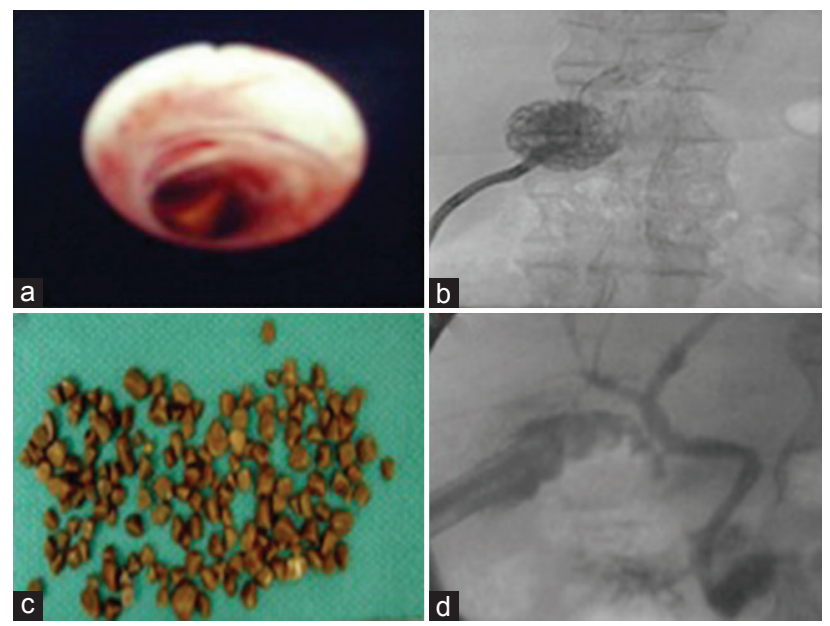

Figure 1: (a) Gallbladder with gallstones, (b) Cholangiogram demonstrates multiple gallbladder stones with serial dilation of the sinus tract for 2-4 weeks and removal of stones with the basket, (c) gallstones after removal, (d) postremoval of gallbladder stone cholangiogram showed patency cystic and the common bile duct with flow of contrast to duodenum

solitary large stone removed percutaneously using Olympus ultrasonic lithotripter (LUS-1) mini perk rigid scope $20 \mathrm{Fr}$ [Figure 2].

No recurrence of symptoms or gallstones was noted in all patients at 3-year follow-up as confirmed by surveillance ultrasonography.

\section{Discussion}

Laparoscopic cholecystectomy has become the mainstay of treatment of symptomatic gallstones with mortality rate of $2 \%$. Conventional open cholecystectomy is still performed in selective cases with equally good results.

Laparoscopic or conventional cholecystectomy are associated with high morbidity and mortality in patients with multiple comorbidities such as severe ischemic heart, liver cirrhosis disease, and respiratory and renal failure. ${ }^{[4]}$ In such cases, percutaneous cholecystostomy is done for urgent decompression and relief of acute symptoms. Later, further treatment is needed to avoid future complications due to gallstones. Extracorporeal shock wave lithotripsy (ESWL) is an option of treatment for such patients, but it can cause biliary pancreatitis and liver hematoma. Only $10 \%-25 \%$ of patients are suitable for ESWL. ${ }^{[5]}$ Tandan and Reddy reported that ESWL followed by endoscopic retrograde cholangiopancreatography is as good as surgery for clearance of the ducts and pain relief. ${ }^{[6]}$ Percutaneous cholecystolithotomy (PCCL) is another alternative for high-risk patients who are not candidate for general anesthesia. ${ }^{[7]}$ This procedure can be performed either transperitoneal or transhepatic approach. PCCL is a safe procedure for high-risk patients, and it may achieve complete gallstone removal in more than $85 \%{ }^{[8,9]}$ One drawback of this procedure is the recurrence of gallstones. Zou et al. reported that the chances of

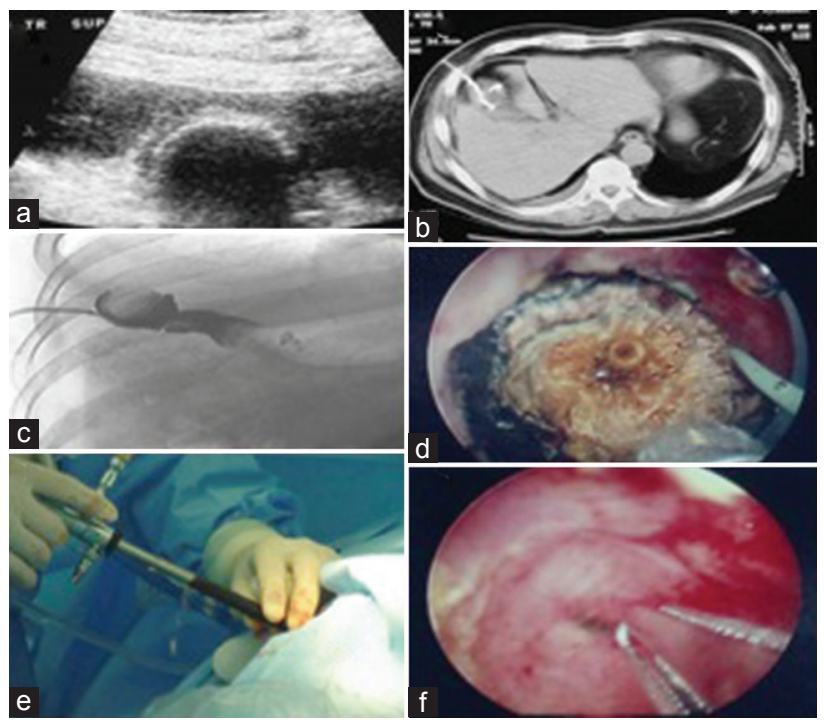

Figure 2: (a) Ultrasonography showed large gallbladder stone as a wall, echo, and shadow sign. (b) Computed tomography showed percutaneous 8.5 Fr catheter in the gall bladder. (c) Cholangiogram showed large gallbladder stone. (d) Endoscopic view of large gallbladder stone. (e) (Mini perk rigid scope $20 \mathrm{Fr}$ ) Solitary large stone removed percutaneously using ultrasonic lithotripter. (f) Empty gallbladder after removal of stones

recurrence of gallstones are high within 5-6 years of PCCL. Nonetheless, PCCL is a safe procedure in high-risk patients with limited life expectancy and provides better quality of life. ${ }^{[10]}$ Complications of PCCL are intraperitoneal bile leak and liver hematoma due to vascular injury. Transperitoneal approach is appropriate for patients with liver disease and coagulopathy. ${ }^{[11,12]}$

In summary, PCCL may be a safe and less invasive method alternative to surgery in high-risk and critically ill patients with acute calculus cholecystitis.

Financial support and sponsorship

Nil.

\section{Conflicts of interest}

There are no conflicts of interest.

\section{References}

1. Soper NJ. Cholecystectomy: From Langenbuch to natural orifice transluminal endoscopic surgery. World J Surg 2011;35:1422-7.

2. Burhenne HJ. Electrohydrolytic fragmentation of retained common duct stones. Radiology 1975;117(3 Pt 1):721-3.

3. Burhenne HJ, Stoller JL. Minicholecystostomy and radiologic stone extraction in high-risk cholelithiasis patients. Preliminary experience. Am J Surg 1985;149:632-5.

4. Winbladh A, Gullstrand P, Svanvik J, Sandström P. Systematic review of cholecystostomy as a treatment option in acute cholecystitis. HPB (Oxford) 2009;11:183-93.

5. Tandan M, Reddy DN, Santosh D, Reddy V, Koppuju V, Lakhtakia S, et al. Extracorporeal shock wave lithotripsy of large difficult common bile duct stones: Efficacy and analysis of factors that favor stone fragmentation. J Gastroenterol Hepatol 2009;24:1370-4.

6. Tandan M, Reddy DN. Extracorporeal shock wave lithotripsy 
for pancreatic and large common bile duct stones. World $\mathrm{J}$ Gastroenterol 2011;17:4365-71.

7. Picus D, Hicks ME, Darcy MD, Vesely TM, Kleinhoffer MA, Aliperti G, et al. Percutaneous cholecystolithotomy: Analysis of results and complications in 58 consecutive patients. Radiology 1992;183:779-84.

8. Cope C, Burke DR, Meranze SG. Percutaneous extraction of gallstones in 20 patients. Radiology 1990;176:19-24.

9. Ohashi S. Percutaneous transhepatic cholecystoscopic lithotomy in the management of acute cholecystitis caused by gallbladder stones. Diagn Ther Endosc 1998;5:19-29.
10. Zou YP, Du JD, Li WM, Xiao YQ, Xu HB, Zheng F, et al. Gallstone recurrence after successful percutaneous cholecystolithotomy: A 10-year follow-up of 439 cases. Hepatobiliary Pancreat Dis Int 2007;6:199-203.

11. Gillams A, Curtis SC, Donald J, Russell C, Lees W. Technical considerations in 113 percutaneous cholecystolithotomies. Radiology 1992;183:163-6.

12. Kim HJ, Lee SK, Kim MH, Yoo KS, Lim BC, Seo DW, et al. Safety and usefulness of percutaneous transhepatic cholecystoscopy examination in high-risk surgical patients with acute cholecystitis. Gastrointest Endosc 2000;52:645-9. 